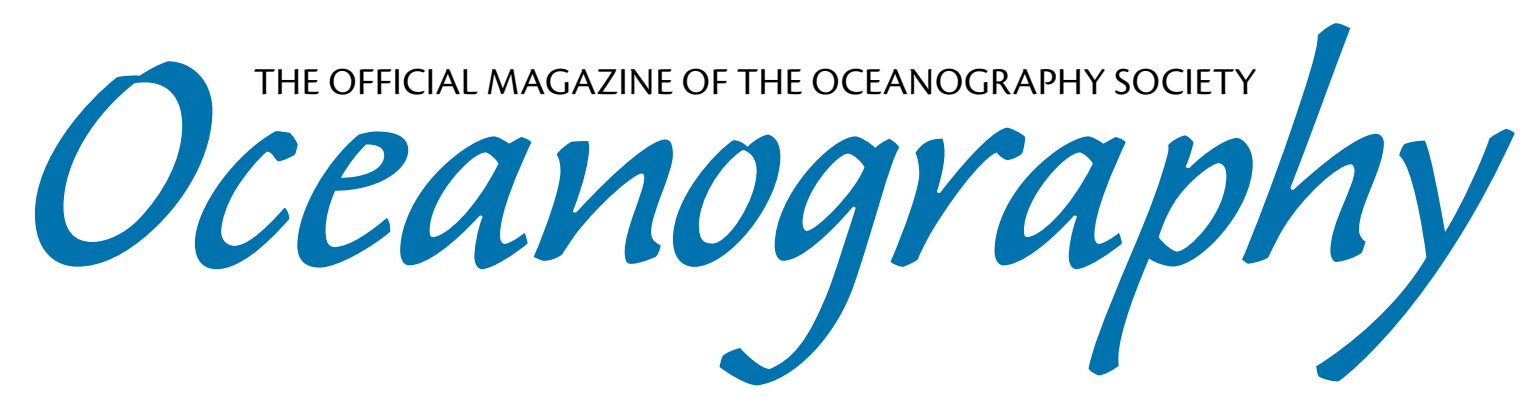

CITATION

Swift, J.H., and A.H. Orsi. 2012. Sixty-four days of hydrography and storms: RVIB Nathaniel

B. Palmer's 2011 S04P Cruise. Oceanography 25(3):54-55, http://dx.doi.org/10.5670/

oceanog.2012.74.

$\mathrm{DOI}$

http://dx.doi.org/10.5670/oceanog.2012.74

COPYRIGHT

This article has been published in Oceanography, Volume 25, Number 3, a quarterly journal of The Oceanography Society. Copyright 2012 by The Oceanography Society. All rights reserved.

USAGE

Permission is granted to copy this article for use in teaching and research. Republication, systematic reproduction, or collective redistribution of any portion of this article by photocopy machine, reposting, or other means is permitted only with the approval of The Oceanography Society. Send all correspondence to: info@tos.org or The Oceanography Society, PO Box 1931, Rockville, MD 20849-1931, USA. 


\title{
Sixty-Four Days of Hydrography and Storms: RVIB Nathaniel B. Palmer's 2011 S04P Cruise
}

\author{
BY JAMES H. SWIFT AND ALEJANDRO H. ORSI
}

Beginning 2003, the United States has systematically reoccupied select hydrographic sections from the 1990s World Ocean Circulation Experiment (WOCE) as part of this country's contribution to the Climate Variability and Predictability (CLIVAR) and Global Ocean Carbon programs of the World Climate Research Programme and International Ocean Carbon Coordination Project. The overarching goal of these efforts is to quantify changes in storage and transport of heat, freshwater, carbon dioxide, and other related parameters.

In brilliant Antarctic weather and rarely seen open waters in McMurdo Sound, we set out on the icebreaking research vessel Nathaniel B. Palmer from the ice pier at the US Antarctic Program McMurdo Station on February 19, 2011, to begin a long-awaited zonal transect of the Pacific Ocean along $67^{\circ} \mathrm{S}$ (Figure 1). The mission of our 64-day cruise was to revisit the Russia-US "S04P" line from the 1992 WOCE cruise on the Akademik loffe research vessel.
In addition, we aimed to close off key CLIVAR meridional transects to the Antarctic shelf break, including completion of transects along $150^{\circ} \mathrm{W}$ and $170^{\circ} \mathrm{W}$.

With nominal spacing of $30 \mathrm{~nm}$, each station consisted of a full-depth deployment of a 36-place rosette/CTD equipped with dual temperature/conductivity channels, pressure and dissolved oxygen instruments, a reference thermometer, a transmissometer, a fluorometer, an altimeter, and an acoustic Doppler current profiler (ADCP). Water samples were collected for measurements of salinity, dissolved oxygen, nutrients, chlorofluorocarbons, dissolved inorganic and organic carbon, total alkalinity, $\mathrm{pH}$, colored dissolved organic matter (CDOM), helium, tritium, oxygen isotopes, ${ }^{14} \mathrm{C}$, and high performance liquid chromatography (HPLC) pigments.

Shallow $(<1,000 \mathrm{~m})$ trace metal rosette casts were planned at every second station. Underway shipboard measurements included
$\mathrm{ADCP}$, surface temperature/salinity/p $\mathrm{CO}_{2}$, and other seawater properties, meteorology, solar radiation, and aerosols/precipitation. US data and accompanying documentation are publicly available at the CLIVAR and Carbon Hydrographic Data Office (via http://ushydro. ucsd.edu) and the Carbon Dioxide Information Analysis Center (http://cdiac.ornl.gov).

As we neared Cape Adare to start the first station, winds rose well past 30 knots and continued to roughen the seas during the day. This weather was a taste of the future, because storms frequently interrupted our work (e.g., 105 hours were lost in the first two weeks of the cruise alone), but the new data were fascinating from the start.

At the western boundary of the Ross Gyre (Figure 2), both Antarctic Surface Water (AASW) and Bottom Water (AABW) were lighter in 2011 than they had been in 1992the top $200 \mathrm{~m}$ layer at the deeper stations (13-18) by $0.15 \mathrm{~kg} \mathrm{~m}^{-3}$ due to a 0.15 decrease

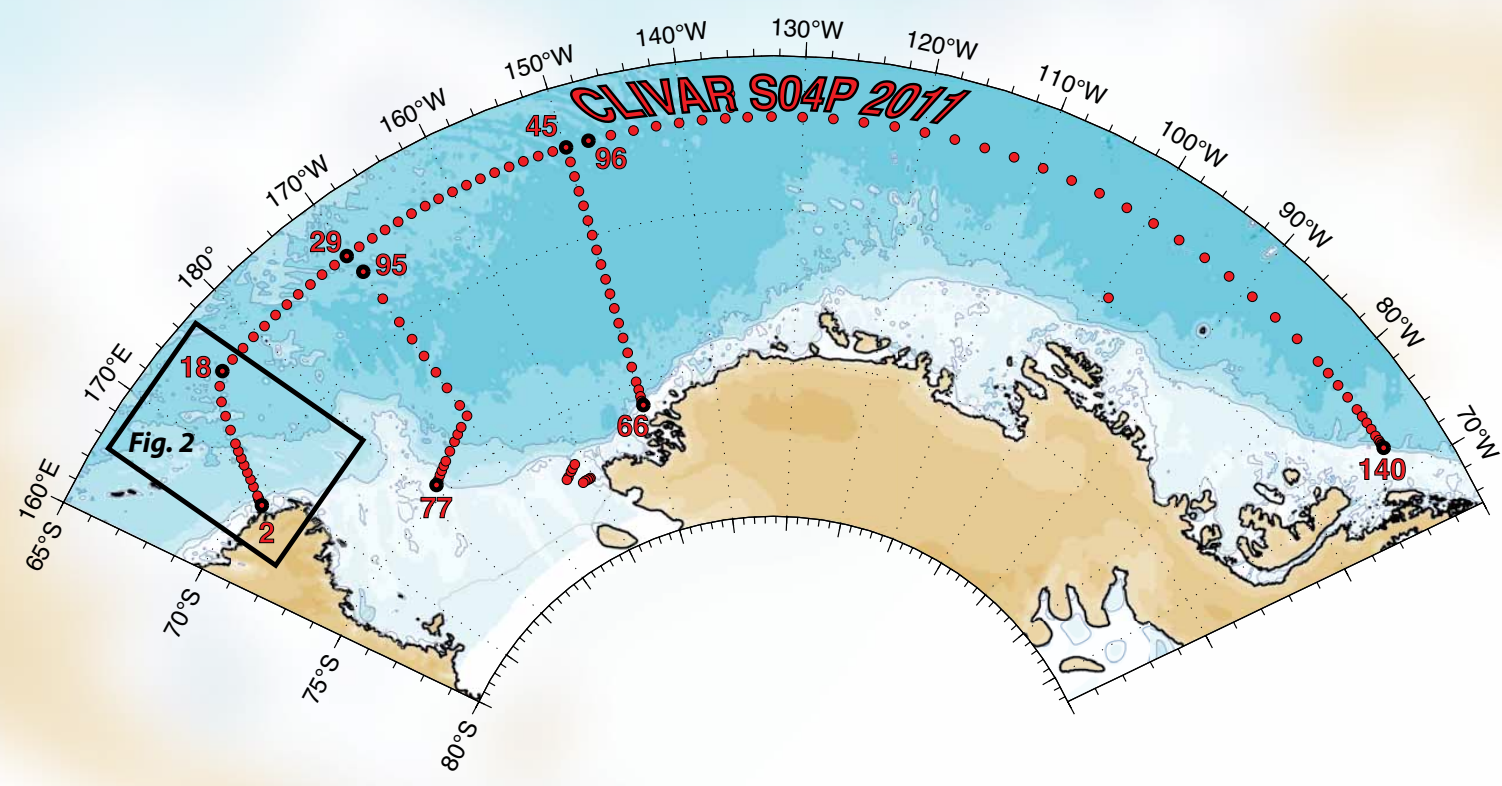

Figure 1. Locations of stations occupied by RVIB Nathaniel B. Palmer in early 2011 during the S04P cruise part of the US Climate Variability and Predictability (CLIVAR) and Global Ocean Carbon programs of the World Climate Research Programme and International Ocean Carbon Coordination Project. The western box enclosing stations $1-18$ shows the area illustrated in Figure 2. 


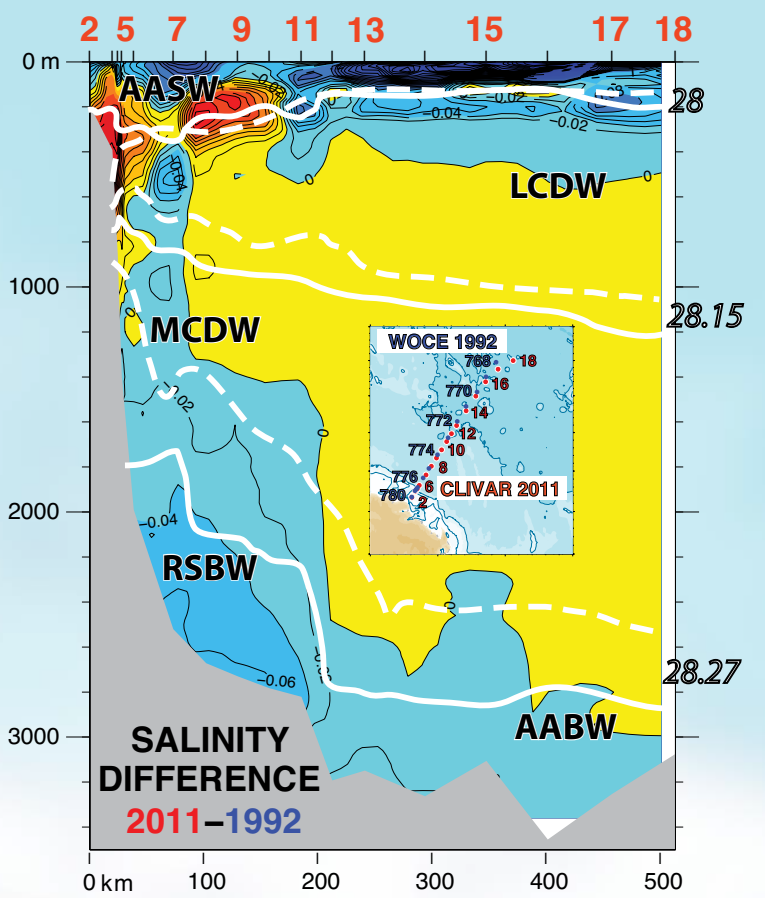

Figure 2. Vertical distribution of salinity differences

between 2011 (CLIVAR) and 1992 World Ocean Circulation

Experiment (WOCE) calculated using repeat CTD measurements at the western end of the S04P line, within the small box shown in Figure 1. In areas with positive (negative) values, the salinity has increased (decreased), and they are shaded in, from smallest to largest changes, with yellow (light blue) to red (dark blue) colors. The solid and dashed white lines are the 2011 and 1992 traces of particular isopycnals (i.e., the surfaces with neutral density values of $28 \mathrm{~kg} \mathrm{~m}^{-3}, 28.15 \mathrm{~kg} \mathrm{~m}^{-3}$, and $28.27 \mathrm{~kg} \mathrm{~m}^{-3}$ ) separating Antarctic Surface Water (AASW), Lower and Modified Circumpolar Deep Water (LCDW and MCDW), and Antarctic Bottom Water (AABW) and newly formed Ross Sea Bottom Water (RSBW). The location of WOCE stations 768-790 from 1992 are indicated with blue dots in the inset map, and the red dots correspond to stations 2-18 from the 2011 CLIVAR cruise.

in salinity, and waters below $1,750 \mathrm{~m}$ at shallower stations (6-12) by $0.06 \mathrm{~kg} \mathrm{~m}^{-3}$ due to significant warming of $0.1^{\circ} \mathrm{C}$ and only a 0.04 salinity reduction.

That the saltiest (> 34.71) and densest $\left(>28.40 \mathrm{~kg} \mathrm{~m}^{-3}\right.$ ) newly formed Ross Sea Bottom Water (RSBW) measured at the foot of the slope during WOCE was no longer present in 2011 was a shock. Instead, the bulk outflow of RSBW in 2011 was lighter than $28.35 \mathrm{~kg} \mathrm{~m}^{-3}$ and fresher than 34.68. In addition to rapid warming and freshening, the thickness of the AABW layer exported from the Ross Sea shelf has diminished by a couple of hundred meters between 1992 and 2011. Also, a more prominent low-salinity mixture of local Lower Circumpolar Deep Water and AASW, known as Modified Circumpolar Deep Water, was observed in 2011 between $800 \mathrm{~m}$ and 1,500 m over the slope (stations 6-12). A thickened Modified Circumpolar Deep Water layer above $A A B W$ suggests more direct ventilation of the adjacent deep ocean along intermediate density layers in recent years. In contrast, the shallower (200-600 m) source Circumpolar Deep Water at stations over the slope (stations 2-12) was much warmer $\left(0.6^{\circ} \mathrm{C}\right)$ and only slightly saltier (0.008) in 2011 than in 1992.
Navigation to the shelf along $150^{\circ} \mathrm{W}$ (and later away from the shelf along $170^{\circ} \mathrm{W}$ ) was not seriously impeded by weather or ice, but our progress near the shelf break toward two moorings in the eastern Ross Sea (the cluster of five shelf stations near $160^{\circ} \mathrm{W}$ ) was slow and around patches of thick ice tens of kilometers long. Yet these transits were scenic highlights of the voyage, with abundant wildlife and spectacular forms of ice. At this point, the cruise's toppriority work had been accomplished before mid-cruise, despite losing more than seven days to bad weather. In the end, we completed as many stations (140) as feasible and achieved our objectives within the scheduled time and fuel.

An incredible coincidence occurred about a week before the end of our cruise. A signal had been received at a land-based station from a $400 \mathrm{~m}$ long biophysical mooring deployed more than 10 years earlier by Jim Ryder of Woods Hole Oceanographic Institution, who was also the mooring tech on our cruise, at a location only about eight hours away in $450 \mathrm{~m}$ of water. This "ghost" mooring was assumed lost after failing to rise to the surface when triggered to do so back then. So, after our last and easternmost station, the Palmer moved to the mooring's last reported location and-voilà!- there it was. The entire string of instruments, fully adorned with a decade's worth of marine growth, was finally recovered. This unexpected recovery marked the end of a successful expedition, and the results from these new high-quality data sets will continue to improve our understanding of ongoing changes in the water mass properties and circulation of the Southern Ocean.

\section{ACKNOWLEDGEMENTS}

CLIVAR S04P was supported by the National Science Foundation's Division of Ocean Sciences grants OCE-0919454, OCE-0752970, OCE0752972, OCE-0752980, OCE-0825163, OCE0962393, OCE-0962158. We are also grateful for at sea support on RVIB Nathaniel B. Palmer from Edison Chouest Offshore and technicians from Raytheon Polar Services Corporation.

\section{AUTHORS}

\section{James H. Swift (jswift@ucsd.edu)} is Research Oceanographer, Scripps Institution of Oceanography, University of California, San Diego, CA, USA.

Alejandro H. Orsi is Associate Professor, Department of Oceanography, Texas A\&M University, College Station, TX, USA. 